\title{
The Application of Vessel Integrated Automation Systems to Improve Ship Safety and Security
}

\author{
Agoes Santoso ${ }^{1, a, *}$, Indra Ranu Kusuma ${ }^{1}$ and Jerome Lin ${ }^{2}$ \\ ${ }^{1}$ Department of Marine Engineering, Institut Teknologi Sepuluh Nopember, Surabaya, Indonesia \\ ${ }^{2}$ PRAXIS Far East Automation Ltd., Singapore \\ a.agoes@its.ac.id \\ *corresponding author
}

\begin{abstract}
Keywords: Vessel Integrated Automation System, i-system, patrol boat, life cycle warranty.

Abstract: Vessel Integrated Automation System (VIAS) offers higher performances in operational, monitoring, data sharing, maintenance system, solution, and possibly intelligence system that can improve ship performances. VIAS also performs easier of ship operations, crew efficiency, early warning system, and higher levels of both safety and security. On this paper the VIAS applied to the $38 \mathrm{~m}$ patrol boat. Code will be generated on the forms of virtual monitoring, installation diagram, mimic, and operation desk. The existence of VIAS onboard a ship is expected to technically improve the entire ship performances in terms of safety, security and longer life cycle.
\end{abstract}

\section{Introduction}

Safety placed in the top priority in all phases from design, fabrication, operation, till maintenance. Under operation, one of method called as Safety Management System (SMS) is required by all responsible persons and their vessels that must comply with the requirements of Chapter IX of the International Convention for the Safety of Life at Sea (SOLAS), 1974, and International Safety Management (ISM) Code for the Safe Operation of Ships and Pollution Prevention, adopted in London on May 24,1994. SMS is an important aspect of the ISM code and it details all the important policies, practices, and procedures that are to be followed in order to ensure safe functioning of ships at the sea. All commercial vessels are required to establish safe ship management procedures [5]. SMS should be implemented by the shipping companies to ensure safety of the ship and marine environment. SMS has 12 sections as; General, Safety and Environment Policy, Company Responsibilities and Authori- ties, Designated Person DP, Master's Responsibility and Authority, Resources and Personnel, Operational Procedures, Emergency Procedures, Reporting Accidents/Incidents, Maintenance and Recording, Documentation, and Review and Evaluation.

Security also become a big issue in the ship operation. IMO develop ISPS as a part of SOLAS. The ISPS Code is a set of measures to enhance the security of ships and port facilities as a response after the 9/11 attacks. Security system may come in form of specific new equipment, tools, methods, and even reporting and documentation. Together with the safety issue, the security level will be 
investigated when a VIAS implemented to the 38meter fast patrol boat as shown in Figure 2. Vessel Integrated Automation System (VIAS) developed in purpose to improve ship operation performances related to fuel efficiency [6], environment friendly, comfortability, safety and security by applying effective method for monitoring, data sharing, maintenance scheduling, and problem solution. VIAS can be developed for an intelligent-system [9] and possibly Unmanned/Autonomous Vessel. The advantages of integrated system are easier ship's operation, shortage Crews number, early warning, and higher level of safety [7] and security. Figure 1 shows the hierarchy in the development of a VIAS.

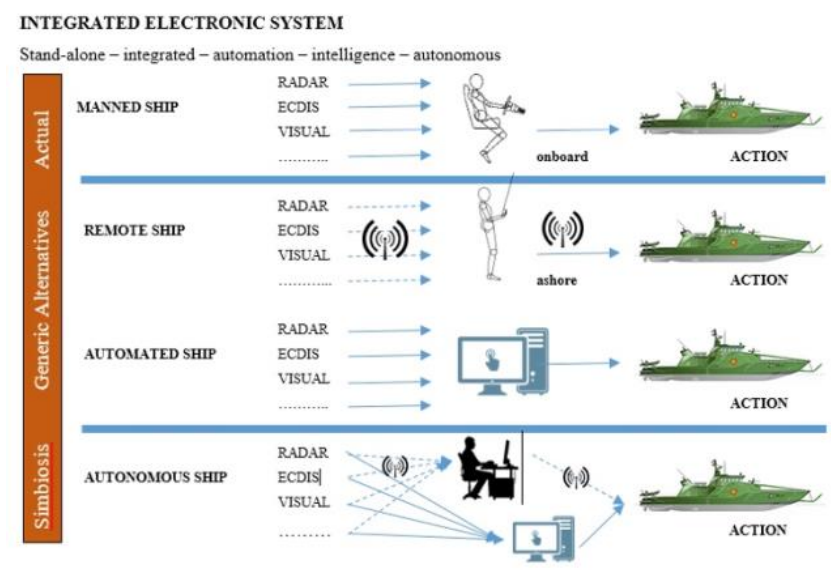

Figure 1. Hierarchy of the development Vessel Integrated Automation

The primary aim of the design of the VIAS is survivability and continuity (reliability) of the ship's operation. Survivability relates to the ability of the power system both propulsion and auxiliary, even when damaged, to support the ship's ability to continue fulfilling its missions to the degree planned for a particular threat. It is important capability for patrol boat especially when operated by military missions. VIAS also must warranty availability of power in efficient solution, performing diagnostic, warning system and alarms [1], and intelligent override system both locally and remotely using Internet Ship View technology [4]. It may ship-owner possibly to know the ship condition in real time from office. VIAS integrates in monitoring and control of the propulsion and power, auxiliary machinery, fire alarm system, cargo, ballast, navigation system, CCTV, alarming, and lighting management.

There are many study in identification of hazard that are influences of ship's safety. One of the study shows the ranking of hazard analysis are problem in head situation (index of 6.56), error of navigation (index of 6.13), failure of machinery and electricity (index of 5.9), problem in crossing situation (index of 5.8), bad weather (index of 5.75), over traffic density (index of 5.23), problem in overtaking situation (index of 4.68), close distance among vessels (index of 3.56), speed (index of 2.87), bad area characteristic (index of 1.16). How the VIAS can minimalized the hazards above will be pointed in discussion.

\section{Methods and Data}

This paper study the application of VIAS to 38 meters fast patrol boat designed for Indonesian Army. It is important idea to empowering Indonesian shipyard industries to build their own patrol boats [2]. Empowering not only in the aspect of quantity but also must consider about quality. So far, local products can be stated as a stand-alone system. Built-in automation system called as ECU in main engines only operated to control the operation of the engines, electronic control may available on pumps unit only control its system, etc. All stand-alone systems onboard above can be controlled 
together and integrated to automation level by using proper and reliable interfaces. One of the way to improve the quality of the ships that can built by Indonesian shipyards [3].
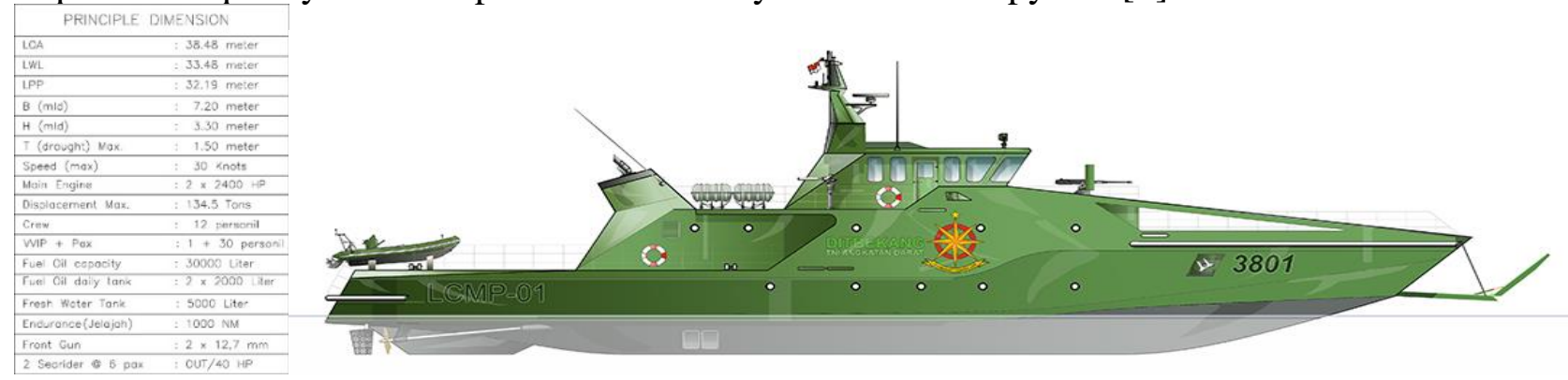

Figure 2. Model design of the 38 meters Patrol Boat

Common questions may come in the application of VIAS to this 38 meters patrol boat. Is it feasible economically to apply VIAS onboard a small craft? Smaller size of the ves sel means less complicated of systems. This assumption may not true for a military patrol boat. High speed capability of the patrol boat insist of bigger engines, excellent maneuvering and stability, complete navigation and communication system, protection system such as fire and alarms system, CCTV system, and defense/offense system. All the requirements not only need supporting installation such as cabling and piping. Manpower onboard a ship facing a human error risk. The existence of the automation system possible to reduce the number of crews. Even Class Society based on enumeration of the SOLAS 1974 Chapter II-1, regulations 46 to regulation 53, provides a notation called as UMS (Unattended Machinery Space) for automation system in engine room. UMS deal with fire precaution, protection against flooding, centralized and controlling machinery from Bridge, automatic fire detection and extinguishing, comprehensive alarm system, and auto-start of emergency generator. VIAS can provide all requirements in tidy and compact arrangement as shown in Figure 3 for designed $38 \mathrm{~m}$ patrol boat. It come not only by smaller hardware used but also from optimize cabling, modules and panels.

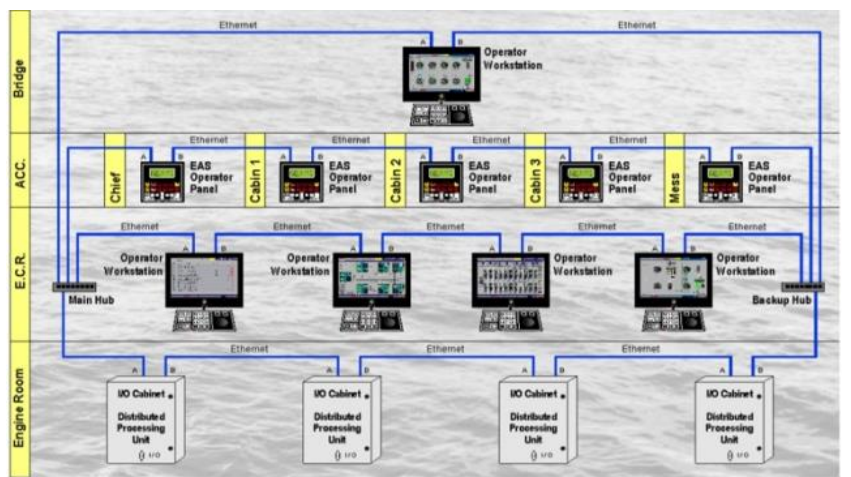

Figure 3. Integrated alarm and monitoring systems.

The method of study is use the qualitative standard of the SMS and Hazard Analysis to investigate how big the benefits of the VIAS in order to improve safety and security onboard a ship especially a 38 meters patrol boat. The particular data of the ship will be show in Figure 2 with the profile-view of the designed ship. The appearance of VIAS onboard support ship navigation and operation of the platform only. There is no discussion about Control system for weapons neither Combat Management System (CMS). 


\section{Results and Discussion}

Generally speaking, Safety and Security can be improved by using new technology such as VIAS to aid the navigation of the ships, avoid human errors, and provide redundancy system with predictive machinery health management. VIAS offers three important points, smarter, greener, and data driven. As stated before, the capability of the VIAS will be discussed based on the 12 sections of SMS.

Safety and Environment Policy will comply with ISM Code. VIAS can identified all possibly risk of damage and provide safeguard system by introduce comprehensive alarms system for fire protection and extinguisher system, navigation operation, auto-start stop emergency generator and backup system, and BNWAS. Environmental and minimize energy policy can be easy to follow up when VIAS also offers Green solution technology.

Company Responsibilities and Authorities improved when they can be registered and recorded on the VIAS operation system. Army base using VIAS can document the responsibility, authority, and interaction of all personnel who manage, perform, and verify work relating to and affecting safety and pollution prevention. VIAS capable monitor and even control the operation of the ship in real time just sit on the office by the existence of the Internet Ship View technology. Data can be accessed from giant monitor to small gadget. Implementing tight authority accesses means higher security level.

Designated Person Ashore (DPA) has direct access to the highest level of management to ensure the safe operation of each ship and provide a link between the company and those on board. DPA can access specific room onboard the ship. Virtually, DPA also has unique password when accessing highest level data of VIAS. It may solve the problems in monitoring fuel consumption when DP and Owner capable of monitoring engine running data. Internet Ship Views simply DPA duty on internal audits, treatment on non-conformities, exchange of information, and communication in rarely visit onboard.

Elected Master has responsibility and Authority to implementing the safety and environmental protection policy, motivating the crew in the observation of that policy, issuing appropriate orders and instructions in a clear and simple manner, verifying that specified requirements are observed, and reviewing the SMS and reporting its deficiencies to the shore based management. Comprehensive and complete documentation recorded by VIAS improve Master ability to make more precise decisions about safety and environmental pollution.

Resources and Personnel in implementing SMS can be improved by VIAS due to easy operation and unattended situation when the integrated automation exist onboard. VIAS offers less specialized and ship crew can say, know little bit about a lot. It is advantage in shortage the number of crews.

Operational Procedures should be established to show the detail of the plans and instructions for key vessel operations concerning the safety of the ship and the prevention of pollution. The various tasks involved should be defined and assigned to qualified personnel. This information should be easily understood by all relevant shipboard personnel. Easy operation and comprehensive warning system of VIAS offers shorten procedures of operation that may be minimize human error under One push button mode.

Emergency Procedures should be established to prepare for various emergencies involving pollution and the safety of the vessel, crew, and passengers. The various tasks involved should be defined and assigned to qualified personnel. Comprehensive warning system, easy for drill routine, and identification system of VIAS offers shorten procedures of operation that may be minimize risk and loss.

Reporting Accidents/Incidents should include procedures in the SMS to ensure that hazardous situations, accidents, non-conformities, and discharges of oil and garbage are reported, investigated, and analyzed. The company should also ensure that corrective actions are implemented and verified. 
VIAS record any alarm and override system. This capability can be improved to be intelligent system for overcome the problems numerically.

Maintenance can be managed by VIAS in proactive method based on Condition Monitoring technic. Two keys performance is sensors and remote sensing. And Recording system is the heart of this method. VIAS can provide input/output slot up to 24.000 ports in one ship.

Documentation of the SMS is important to the effectiveness of the system. SMS documentation includes only what is necessary to cover the application of the system and is organized in a clear and effective way. VIAS has excellent documentation system that is not only controlled onboard but also can be accessed from office in real time. It is offers safe backup and sharing information between onboard and office.

Review and Evaluation. A policy should be developed to ensure that procedures developed within the SMS are followed properly and in accordance with regulations. VIAS database provides excellent documentation system that consequently offers easier and faster periodic review and evaluation for DPA.

\subsection{Hazard Analysis Ranking}

Related to Hazard analysis ranking [7], VIAS may overcome the problem in head situation and error of navigation by integrated navigation system which are Autopilot, Radar, GPS, ECDIS, and AIS could work as redundant system. More information cause more precise data to decide and solve the problems. Integrated navigation system under VIAS offers more advantages due to the existence of comprehensive alarms and early warning systems.

VIAS offers PMS and PCS technology based on redundancy and balanced load sharing which failures of machinery and electricity system can be avoided. PMS capable of running engine based on optimum speed that impact on the longer lifetime. PCS can operate automatically every generatorset in duty and as backup mode. Auto synchronous also protects the generator-set from miss-operation or overload.Any text or material outside the aforementioned margins will not be printed.

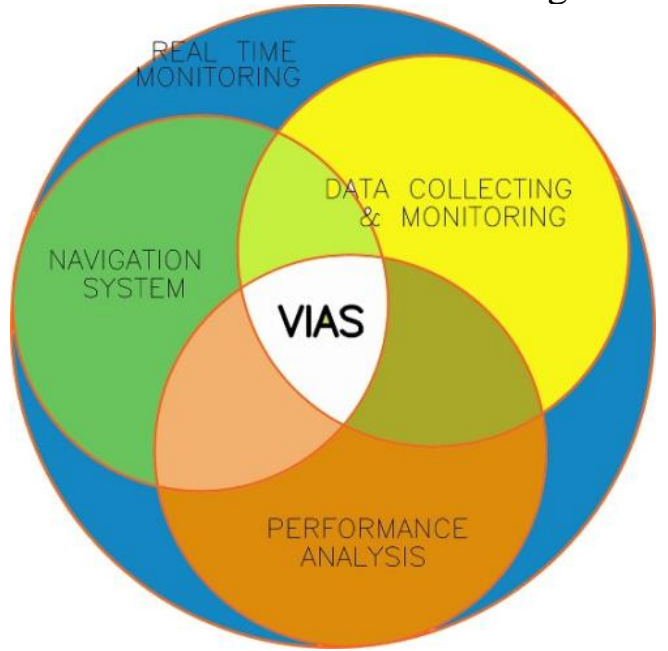

Figure 4. Intersection to perform VIAS

Problems in crossing situation, bad weather, over traffic density, problems in overtaking situation, close distance among vessels, speed, and bad area characteristic can be minimized by well sharing information that is supporting by VIAS navigation and communication system onboard. Information and data come easily from another ship or send by office and port authority. Integrated BNWAS, EWS and Autopilot with VIAS make better guidance during ship operation under the conditions above. Availability internet on the ship and capability to access and sharing any information and data 
by using portable gadget or smart-phone results authorized crews always keep in touch with his duty and responsibility.

Figure 4 shows that VIAS is performed by the intersection of the operation of the navigation system and ship power management, controlled under performance analysis combined with the comprehensive data collecting and monitored in the real time conditions. Integrated the three components to be a VIAS under real time monitoring means not only improve the redundancy systems but also warranty the availability and reliability of the ship's operation. It is a key component in improving safety and security

\section{Conclusions}

SMS is developed by USCG as a part of military Board. It may useful for Indonesian Army or Navy to follow the regulations in order to improve ship safety and security. The application of VIAS improve the level of ship safety and security due to minimize human error, redundancy of the sensors, wide coverage of control and monitoring, and accurate alarm system. Availability power achieved excellently by combine PCS and PMS that fully supported by IAMS to perform VIAS. Its affects not only efficient operation but also longer life cycle. The 38 meters fast patrol boat is a small craft type that it can be possibly developed as a manned ship with UMS notation, remote ship, integrated automation ship, or autonomous ship.

\section{References}

[1] Baldauf M., K., Baumler, Nakazawa T., Benedict K., and Schaub M., (2013), Energy-efficient Ship Operation Training Requirements and Challenges, The International Journal on Marine Navigation and Safety of Sea Transportation, TRANSNAV, vol. 7, Number 2, June 2013, Poland

[2] Doerry N., Robey H., Amy J., and Petry C., (1996), Powering the Future with the Integrated Power System, NAVAL ENGINEERS JOURNAL, May 1996, USA

[3] Lebkowski R., Smierzchalski W., Gierusz, and Dziedzicki K., (2008), Intelligent Ship Control System, Gdynia Maritime University, Gdynia, Poland, International Journal on Marine Navigation and Safety of Sea Transportation Volume 2 Number 1 March 2008

[4] Lin J., (2017), PRAXIS Ship Automation, Guest Lecturer slide presentation for Department of Marine Engineering ITS, 22 November 2017, Surabaya Indonesia

[5] Santoso A., Gerianto I., (2012), Peningkatan kemampuan rancang bangun naval-ship dalam negri untuk mewujudkan kemandirian bangsa, Seminar Nasional Teknologi Kelautan VII (SENTA) ITS 5 Desember 2012, Seminar FTK 2012

[6] Santoso A., Lin J., Kusuma I.R., and Koenhardono E.S., (2017), Penerapan Sistem Elektronik Terintegrasi Pada Rancang Bangun Kapal Patroli Buatan Dalam Negeri untuk Meningkatkan Kemandirian Bangsa didalam Menjaga Kedaulatan Maritim, Seminar Nasional MASTER 2017, pp. 227-230, PPNS Surabaya, Indonesia

[7] Shtay A.D., Gharib W., (2009), An Intelligent Control System for Ship Collision Avoidance, International Journal of Engineering \& Technology IJET-IJENS Vol:09 No:10, December 2009

[8] USCG, (2011), Safety Management System Manual Guidebook", (https://homeport.uscg.mil/Lists/Content), last modified at 1/10/2011 9:50 by svc-hipprd-cdeploy, USA

[9] Zaman M.B, Santoso A., Kobayashi E., Wakabayashi N., and Maimun A., (2015), Formal Safety Assesment (FSA) for Analysis of Ship Collision Using AIS Data, The International Journal on Marine Navigation and Safety on Sea Transportation, pp67-72., Vol.9., No.1., March 2015, Gydnia Poland 